\title{
ß3-Adrenoreceptor Blockade Reduces Hypoxic Myeloid Leukemic Cells Survival and Chemoresistance
}

\author{
Maura Calvani $\left.{ }^{1}{ }^{(}\right)$, Annalisa Dabraio ${ }^{1,2}$, Gennaro Bruno ${ }^{1,2}{ }^{\mathbb{D}}$, Veronica De Gregorio ${ }^{1,2}$, \\ Marcella Coronnello ${ }^{2}$, Costanza Bogani ${ }^{3}$, Sara Ciullini ${ }^{1}$, Giancarlo la Marca ${ }^{4}$, \\ Marina Vignoli ${ }^{1,2}{ }^{\oplus}$, Paola Chiarugi ${ }^{4}$, Margherita Nardi ${ }^{5}$, Alessandro Maria Vannucchi ${ }^{3}$, \\ Luca Filippi ${ }^{6}\left(\right.$ ib and Claudio Favre ${ }^{1, *}$
}

1 Division of Pediatric Oncology/Hematology, Meyer University Children's Hospital, 50139 Florence, Italy; maura.calvani@meyer.it (M.C.); annalisa.dabraio@unifi.it (A.D.); gennaro.bruno@unifi.it (G.B.); veronica.degregorio@meyer.it (V.D.G.); sciulliniman@unifi.it (S.C.); marina.vignoli@unifi.it (M.V.)

2 Department of Health Sciences, University of Florence, 50139 Florence, Italy; marcella.coronnello@unifi.it

3 Department of Experimental and Clinical Medicine, University of Florence, 50139 Florence, Italy; bogani.costanza@gmail.com (C.B.); amvannucchi@unifi.it (A.M.V.)

4 Department of Experimental and Clinical Biomedical Sciences, University of Florence, 50134 Florence, Italy; giancarlo.lamarca@unifi.it (G.1.M.); paola.chiarugi@unifi.it (P.C.)

5 Onco-Hematologic Pediatric Center, University Hospital of Pisa, 56126 Pisa, Italy; m.nardi@med.unipi.it

6 Neonatal Intensive Care Unit, Medical Surgical Fetal-Neonatal Department, Meyer University Children's Hospital, 50139 Florence, Italy; luca.filippi@meyer.it

* Correspondence: claudio.favre@meyer.it; Tel.: +39-0555662739

Received: 31 March 2020; Accepted: 11 June 2020; Published: 12 June 2020

\begin{abstract}
: $\beta$-adrenergic signaling is known to be involved in cancer progression; in particular, beta3-adrenoreceptor ( $\beta 3$-AR) is associated with different tumor conditions. Currently, there are few data concerning $\beta 3$-AR in myeloid malignancies. Here, we evaluated $\beta 3$-AR in myeloid leukemia cell lines and the effect of $\beta 3$-AR antagonist SR59230A. In addition, we investigated the potential role of $\beta 3$-AR blockade in doxorubicin resistance. Using flow cytometry, we assessed cell death in different in vitro myeloid leukemia cell lines (K562, KCL22, HEL, HL60) treated with SR59230A in hypoxia and normoxia; furthermore, we analyzed $\beta 3$-AR expression. We used healthy bone marrow cells (BMCs), peripheral blood mononuclear cells (PBMCs) and cord blood as control samples. Finally, we evaluated the effect of SR59230A plus doxorubicin on K562 and K562/DOX cell lines; K562/DOX cells are resistant to doxorubicin and show P-glycoprotein (P-gp) overexpression. We found that SR59230A increased cancer cell lines apoptosis especially in hypoxia, resulting in selective activity for cancer cells; moreover, $\beta 3$-AR expression was higher in malignancies, particularly under hypoxic condition. Finally, we observed that SR59230A plus doxorubicin increased doxorubicin resistance reversion mainly in hypoxia, probably acting on P-gp. Together, these data point to $\beta 3$-AR as a new target and $\beta 3-\mathrm{AR}$ blockade as a potential approach in myeloid leukemias.
\end{abstract}

Keywords: chemoresistance; myeloid leukemia; $\beta 3$-adrenoreceptor

\section{Introduction}

Leukemia is the term used to identify a group of different cancers involving blood and bone marrow (BM). Myeloid malignancies are clonal disorders associated with uncontrolled proliferation and altered differentiation of hematopoietic stem cells (HSCs) with a consequent increase in immature myeloid cells $[1,2]$. 
In recent years, the development of new technologies and the discovery of novel molecular findings, have improved leukemia diagnosis. An important challenge in the treatment of myeloid malignancies is represented by the phenomenon of resistance to antineoplastic drugs. Understanding the cellular and molecular mechanisms associated with chemoresistance is crucial in order to improve cancer patients' outcome and survival.

There are two main types of chemoresistance: primary drug resistance and acquired drug resistance. In patients with primary resistance, tumor cells appear resistant before chemotherapy; while in patients with acquired resistance, tumor cells become resistant after antineoplastic treatment [3]. In general, drug resistance is the result of a combination of multiple factors and biological mechanisms among which altered expression and activity of specific proteins, genetic and epigenetic changes, deregulation of signal transduction pathways [3,4].

It is known that an abnormal expression of efflux proteins, and especially of P-glycoprotein (P-gp), is associated with chemoresistance in myeloid neoplasms [4-6]. P-gp is an ATP-binding Cassette (ABC) transporter encoded by the multiple drug resistance (MDR1) gene. In particular, it is a 170-kDa efflux pump, which using ATP hydrolysis, plays an important role in the extrusion of different compounds out of cells, including drugs and xenobiotics, with a consequent decrease in intracellular substances accumulation. P-gp is expressed in healthy tissues but also in different types of cancer [7]. Interestingly, P-gp overexpression in tumors, including myeloid neoplasms [4,5], enhances drugs extrusion out of cells, reducing chemotherapy efficiency and promoting the phenomenon of resistance to multiple antineoplastic agents [7]. For instance, an association of a high level of P-gp with a poor outcome is known in acute myeloid leukemia (AML) [4]. Moreover, Schaich et al., reported that MDR1 expression was an independent prognostic factor for induction therapy outcome and overall survival in AML patients [8].

Beta-adrenergic receptors ( $\beta$-ARs) are G-protein-coupled receptors involved in catecholaminesactivated signal transduction pathways. Three types of $\beta$-ARs are known: beta1-adrenoreceptors ( $\beta 1$-ARs), beta2-adrenoreceptors ( $\beta 2$-ARs) and beta3-adrenoreceptors ( $\beta 3$-Ars). These receptors are localized and expressed in distinct and specific tissues. $\beta 1$-ARs are expressed abundantly in cardiac tissue, kidney and adipose tissue; $\beta 2$-ARs are localized in gastrointestinal tract, bronchi, skeletal muscle, liver, immune and non- immune cells; finally, $\beta 3$-ARs are mainly present in intestine, adipose tissue and endothelium, moreover they are expressed in the smooth muscle cells of the detrusor muscle in the urinary bladder [9]. Interestingly, $\beta 3$-ARs expression is reported also in Chinese hamster ovary/K1 cells [10]. $\beta$-ARs are involved in the modulation of different physiological processes, such as metabolism and cardiovascular function, but also in human diseases, including cancer $[9,11]$. Indeed, several studies have described $\beta$-ARs expression in various tumor types and especially in melanoma, vascular tumors and lung, pancreatic, colorectal, brain, breast, ovarian, prostate, hepatic, kidney and adrenal cancer $[9,11]$. Interestingly, $\beta 3$-ARs expression has been reported also in human leukemia cells [12].

$\beta$-ARs play a key role in different biological processes that are crucial in cancer biology and they promote tumor progression [13]. In particular, $\beta$-ARs are involved in inflammation, angiogenesis, cancer cells migration, proliferation and survival, epithelial-mesenchymal transition, invasiveness, metastasis, apoptosis, cellular immune response and resistance to chemotherapy-induced apoptosis $[9,13]$. Among the $\beta$-ARs, the $\beta 2$-AR subtype has been shown to be involved in biological processes related to cancer [14]; however, in recent years, the role of $\beta 3$-AR in the regulation of cancer-related pathways has emerging in different types of cancer, especially in melanoma [15].

Furthermore, $\beta$-ARs expression has been showed not only in cancer cells, but also in tumor microenvironment cells, including cancer associated fibroblasts, macrophages, and endothelial cells $[11,13]$.

Finally, different studies suggest that $\beta$-AR blocker drugs are associated with reduction of cancer cell proliferation, progression and metastasis improving outcome and survival $[9,11]$. For instance, 
B3-AR antagonist SR59230A promotes tumor cells death and reduces angiogenesis and proliferation in melanoma $[9,16]$.

In this study, we investigated the effect of $\beta 3$-AR antagonist SR59230A, belonging to the class of aryloxypropanolaminotetralins, on different in vitro models of myeloid leukemias. Moreover, we analyzed the potential involvement of $\beta 3$-AR in the phenomenon of chemoresistance, which generally represents a crucial challenge in cancer treatment. Indeed, chemoresistance influences patients' clinical outcome promoting recurrence and metastasis and increasing mortality risk.

Here, we demonstrate in in vitro models that $\beta 3$-AR is highly expressed in myeloid malignancies and could be involved in cancer cell lines survival in particular under hypoxic conditions; in addition, we show that SR59230A treatment in combination with doxorubicin could reduce resistance to doxorubicin, especially in hypoxia.

\section{Results}

\subsection{SR59230A Promoted Apoptosis of Leukemia Cell Lines Preferentially in Hypoxia}

In order to investigate the effect of $\beta 3$-ARs blockade on apoptosis in leukemic malignancies, four different cell lines of myeloid leukemia were treated with $\beta 3$-ARs antagonist SR59230A (Figure 1). SR59230A effect was analyzed in K562, KCL22, HEL and HL60 cell lines, using different drug concentrations $(1 \mu \mathrm{M}, 3 \mu \mathrm{M}, 6 \mu \mathrm{M}, 8 \mu \mathrm{M}, 10 \mu \mathrm{M})$ in hypoxic and normoxic conditions, $24 \mathrm{~h}$ and $48 \mathrm{~h}$ after drug treatment.

As reported in Figure 1, SR59230A increased apoptosis with a dose-dependent modality in all cell lines with maximal effects at $8 \mu \mathrm{M}$ and $10 \mu \mathrm{M}$. Moreover, an enhancement of cell lines death was observed in hypoxia and especially after longer drug exposure, $48 \mathrm{~h}$; no relevant differences were observed between $24 \mathrm{~h}$ and $48 \mathrm{~h}$ treatment in normoxia. After $48 \mathrm{~h}$ of treatment most of the cell lines treated underwent apoptosis (ranging from 80\% to 95\%) (Figure 1B). To better discriminate the role played by $\beta 3$-AR, we treated three different myeloid leukemia cell lines (HEL, HL60, K562) with another $\beta 3$-adrenoceptor antagonist, L748,337, and with non-selective $\beta 1 / \beta 2$-AR antagonist propranolol. Results are reported in Supplementary Figure S2A. L 748,337 inhibited all three cell lines at both concentrations ( $5 \mu \mathrm{M}$ and $10 \mu \mathrm{M})$, conversely, propranolol showed a less marked effect on the inhibition of the three cell lines survival. Moreover, to discriminate the role of $\beta 3$-AR in the effect observed following SR59230A and L748,337 treatment, we used selective siRNAs for $\beta 1-, \beta 2-, \beta 3-A R s$ (Supplementary Figure S1A). These results suggested the predominant role of $\beta 3$-AR subtypes in the regulation of cell survival in these leukemia cell lines.

\section{2. $\beta 3-A R$ Expression Increased under Hypoxia in Myeloid Leukemia Cell Lines}

It is known that $\beta 3-\mathrm{AR}$ is highly expressed in different tumor tissues, including hematologic malignancy [17]. Therefore, we investigated the $\beta 3$-AR expression in myeloid leukemia cell lines used in this analysis under normoxia and hypoxia conditions.

Notably, data revealed an increase in 33 -AR expression in K562, HL60 and KCL22 cell lines after $48 \mathrm{~h}$ of hypoxic exposure (Figure 2A), while the HEL cell line showed a different behavior. On the contrary, neither $\beta 1$-AR or $\beta 2$-AR protein expression resulted upregulated under hypoxic conditions (Supplementary Figure S2B). Interestingly, we detected that a high percentage of $\beta 3$-AR-positive cells were also Annexin V-positive, especially in hypoxic conditions after SR59230A treatment, demonstrating an enhancement of apoptosis in $\beta 3$-AR-positive cells. Since the most of $\beta 3$-AR-positive cells were apoptotic, this suggested a selective activity of the treatment with SR59230A on leukemia cell lines (Figure 2B). 
A)
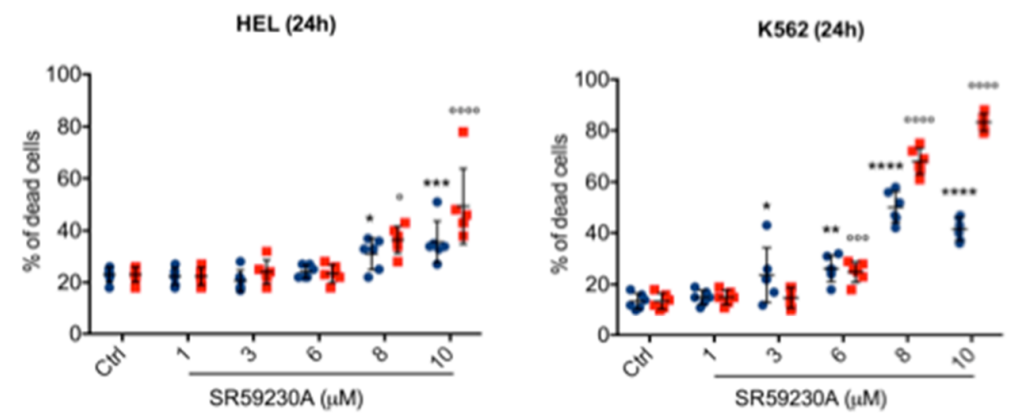

- Normoxia

Hypoxia

KCL22 (24h)

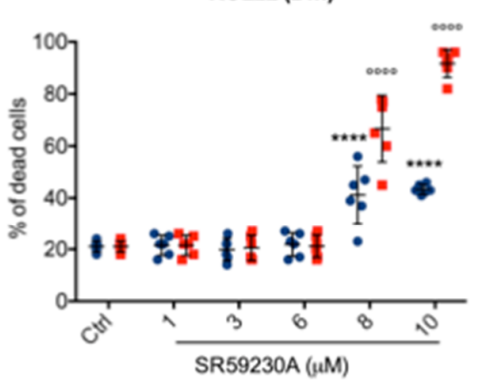

HL60 (24h)

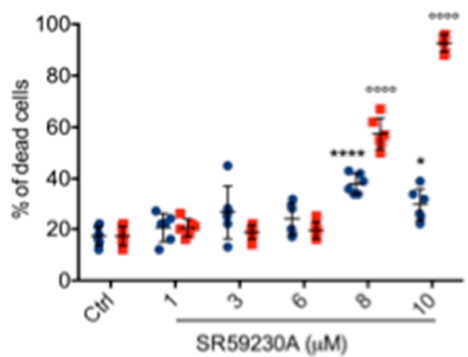

B)
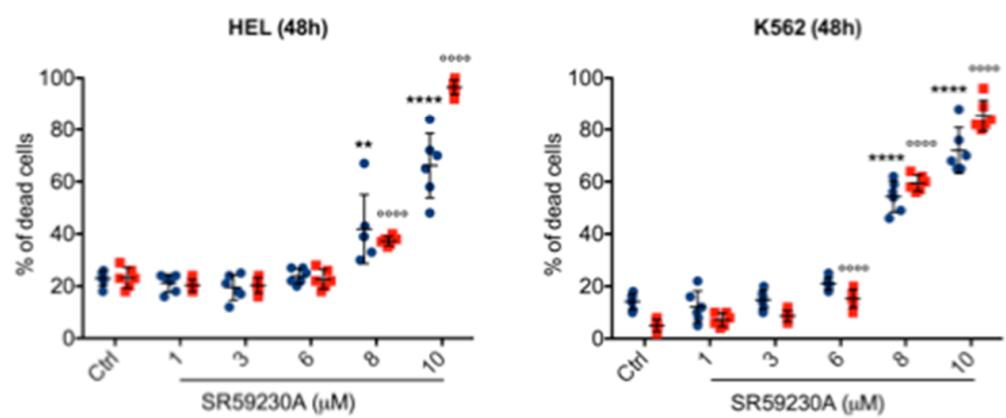

- Normoxia

- Hypoxia
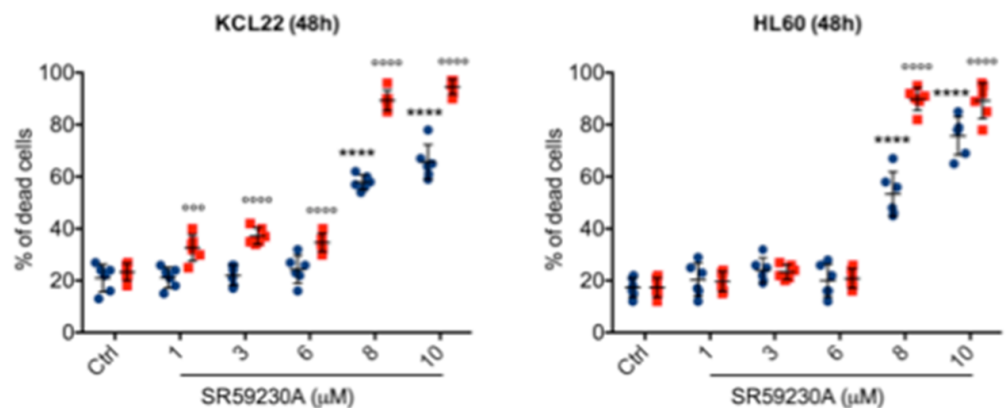

Figure 1. Cell death assessment in myeloid leukemia cell lines treated with SR59230A in hypoxia (1\% $\mathrm{O}_{2}$ ) and in normoxia $\left(21 \% \mathrm{O}_{2}\right)$. (A) Apoptosis evaluation through Annexin $\mathrm{V}$ and Propidium Iodide in HEL, K562, KCL22 and HL60 cell lines treated with different concentrations of SR59230A $(1 \mu \mathrm{M}, 3 \mu \mathrm{M}$, $6 \mu \mathrm{M}, 8 \mu \mathrm{M}, 10 \mu \mathrm{M})$ for $24 \mathrm{~h}$, in normoxia and in hypoxia; (B) apoptosis evaluation through Annexin $\mathrm{V}$ and Propidium Iodide in HEL, K562, KCL22 and HL60 cell lines treated with different concentrations of SR59230A ( $1 \mu \mathrm{M}, 3 \mu \mathrm{M}, 6 \mu \mathrm{M}, 8 \mu \mathrm{M}, 10 \mu \mathrm{M})$ for $48 \mathrm{~h}$, in normoxia and in hypoxia. Significance was calculated by one-way ANOVA analysis followed by Bonferroni's post-hoc test. Results are reported as mean \pm SD of three independent experiments performed in duplicate. $\mathrm{n}=6$ per group. $\left({ }^{*} P<0.05\right.$, ${ }^{* *} P<0.01,{ }^{* * *} P<0.001,{ }^{* * * *} P<0.0001$ SR vs. Ctrl normoxia; ${ }^{\circ} P<0.05,{ }^{\circ \circ \circ} P<0.001,{ }^{\circ \circ \circ \circ} P<0.0001$ SR vs. Ctrl hypoxia). 
A)

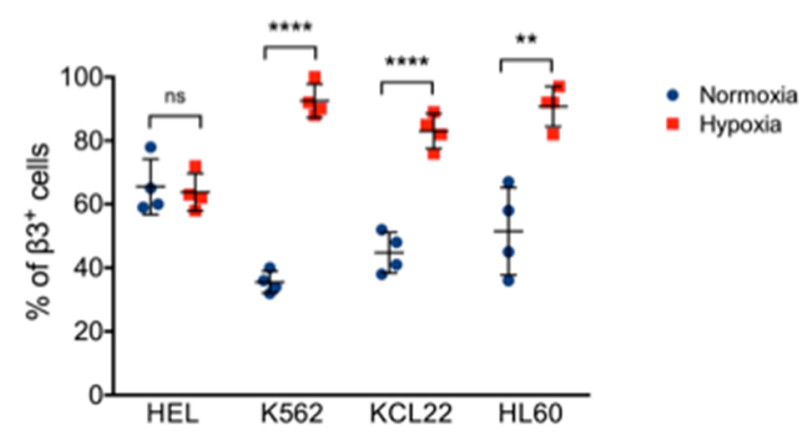

B)

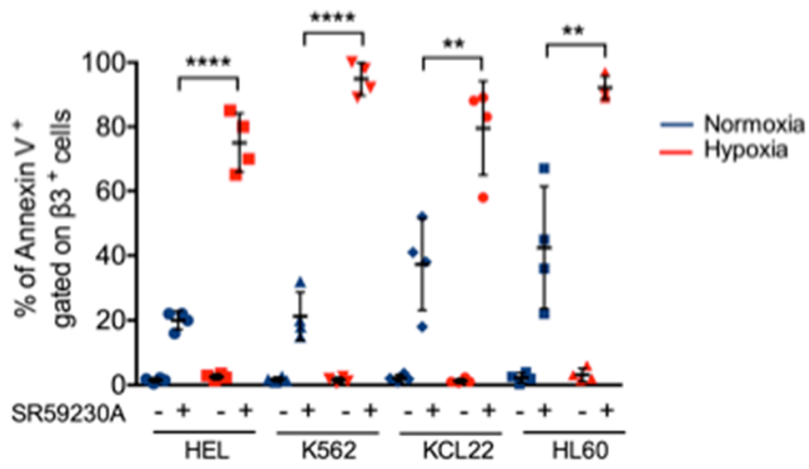

Figure 2. Evaluation of beta3-adrenoreceptor ( $\beta 3-\mathrm{AR})$-positive cells and $\beta 3$-AR/Annexin V-positive cells in myeloid leukemia cell lines under hypoxia $\left(1 \% \mathrm{O}_{2}\right)$ and normoxia $\left(21 \% \mathrm{O}_{2}\right)$ for $48 \mathrm{~h}$. (A) B3-AR-positive cells in HEL, K562, KCL22 and HL60 cell lines in normoxia and hypoxia; significance was calculated by unpaired T-test in each cell line. Results are reported as mean \pm SD of four independent experiments. $\mathrm{n}=4$ per group $\left({ }^{* *} P<0.01,{ }^{* * * *} P<0.0001\right.$ hypoxia vs. normoxia). (B) Flow cytometric analysis of HEL, K562, KCL22 and HL60 cell lines in control and SR59230A $5 \mu \mathrm{M}$ treated cells in normoxia and hypoxia. Annexin V-positive cells gated on a 33 -AR-positive cells subpopulation are showed. Significance was calculated by unpaired T-test in each cell lines. Results are reported as mean \pm SD of four independent experiments. $\mathrm{n}=4$ per group. ${ }^{* *} P<0.01,{ }^{* * * *} P<0.0001$ SR hypoxia vs. SR normoxia).

\subsection{SR59230A Was not Toxic in Healthy Cell Lines}

To exclude drug toxicity, we performed an analysis of SR59230A effect on bone marrow cells (BMCs) samples of healthy donors; in particular, BMCs were treated under normoxia and hypoxia conditions for $48 \mathrm{~h}$.

As shown in Figure 3A, BMCs displayed low sensitivity to SR59230A in comparison to leukemic cell lines, suggesting a possible involvement of $\beta 3-A R$ in cancer cells. Particularly, we observed a relevant BMCs death only at high dose of SR59230A, in a range concentration between 10 and $50 \mu \mathrm{M}$. Moreover, the effect of SR59230A on the colony formation was analyzed in healthy cord blood donor. The presence of SR59230A did not statistically change the number of different colonies (Figure 3B). In the SR59230A groups, under normoxic conditions the number of colony formation units-granulocyte, monocyte (CFU-GM) and burst forming units-erythroid (BFU-E) remained almost stable in all concentrations used.

\subsection{B3-AR Was Expressed at Low Levels in Healthy Cells}

To clarify the ineffectiveness on healthy samples we analyzed the expression of $\beta 3-\mathrm{AR}$ in healthy cells such as BMCs and peripheral blood mononuclear cells (PBMCs). As reported in Figure 4A-D, 
the expression of $\beta 3-A R$ is low in healthy PBMCs and BMCs. Under hypoxic condition, $\beta 3-A R$ resulted slightly upregulated in PBMCs. Among the different subtypes of PBMCs, $\beta 3$-AR resulted in a greater expression in myeloid lineage (Figure 4D). Real time PCR confirmed the low level of $\beta 3-\mathrm{AR}$ in normoxia and a slight induction under hypoxic condition in PBMCs (Figure 4E); moreover, through cytofluorimetric analysis, we observed an increase in $\beta 3$-AR positive cells in BMCs under hypoxic conditions (Figure $4 \mathrm{~F}$ ). All these results supported the hypothesis that $\beta 3$-AR is strongly upregulated in myeloid leukemia cell lines and that it could participate in maintaining cell survival in this pathological condition. Our results showed that $\beta 3$-AR expression increased in cancer, suggesting a potential role of this protein in cancer biology.

A)

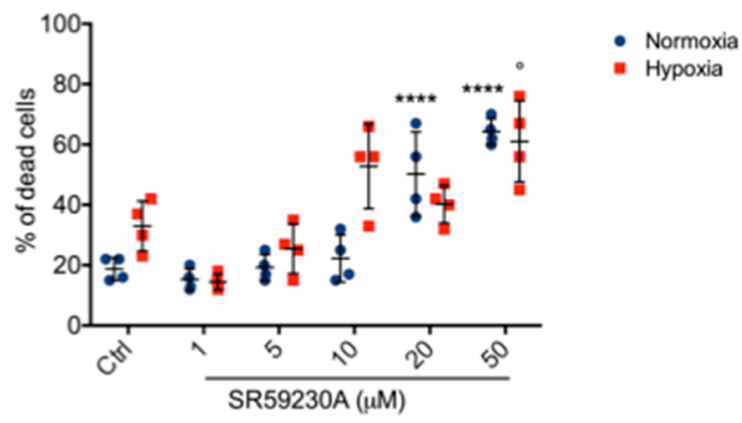

B)

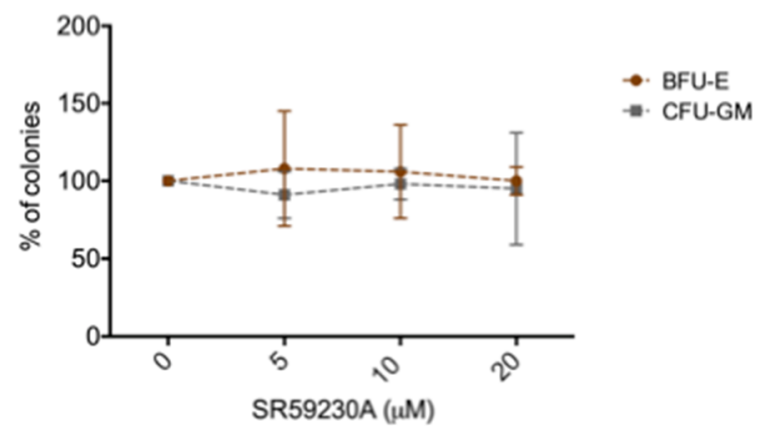

Figure 3. Evaluation of SR59230A effect on bone marrow cells (BMCs) and cord blood samples of healthy donors. (A) Apoptosis evaluation in BMCs samples treated with different concentrations of SR59230A $(1 \mu \mathrm{M}, 5 \mu \mathrm{M}, 10 \mu \mathrm{M}, 20 \mu \mathrm{M}, 50 \mu \mathrm{M})$ in normoxia $\left(21 \% \mathrm{O}_{2}\right)$ and hypoxia $\left(1 \% \mathrm{O}_{2}\right)$; significance was calculated by one-way ANOVA analysis followed by Bonferroni's post-hoc test. Results are reported as mean \pm SD of four independent experiments. $\mathrm{n}=4$ per group. ( ${ }^{* * * *} P<0.0001$ SR vs. Ctrl normoxia; ${ }^{\circ} P<0.05$ SR vs. Ctrl hypoxia). (B) SR59230A ( $\left.5 \mu \mathrm{M}, 10 \mu \mathrm{M}, 20 \mu \mathrm{M}\right)$ effect on colony formation (BFU-E = burst forming units-erythroid; CFU-GM = colony formation units-granulocyte, monocyte) in cord blood samples donor. Results are reported as mean \pm SD of three independent experiments. $\mathrm{n}=3$ per group.

\subsection{K562 Doxorubicin Resistant Cell Line and SR59230A Treatment}

Since SR59230A was very effective in inducing apoptosis in our experimental setting, we evaluated whether SR59230A could sensitize the doxorubicin resistant K562/DOX cell line. SR59230A showed half maximal inhibitory concentration $\left(\mathrm{IC}_{50}\right)$ values which for $\mathrm{K} 562$ and $\mathrm{K} 562 / \mathrm{DOX}$ cell lines were 15.3 and $13.1 \mu \mathrm{M}$, respectively. Therefore, the two lines had the same sensitivity towards the compound. These results led us to continue the studies with two concentrations, $3 \mu \mathrm{M}$ and $5 \mu \mathrm{M}$, which had an intrinsic toxicity of around $20 \%$ (Figure $5 \mathrm{~A}$ ). 
A)
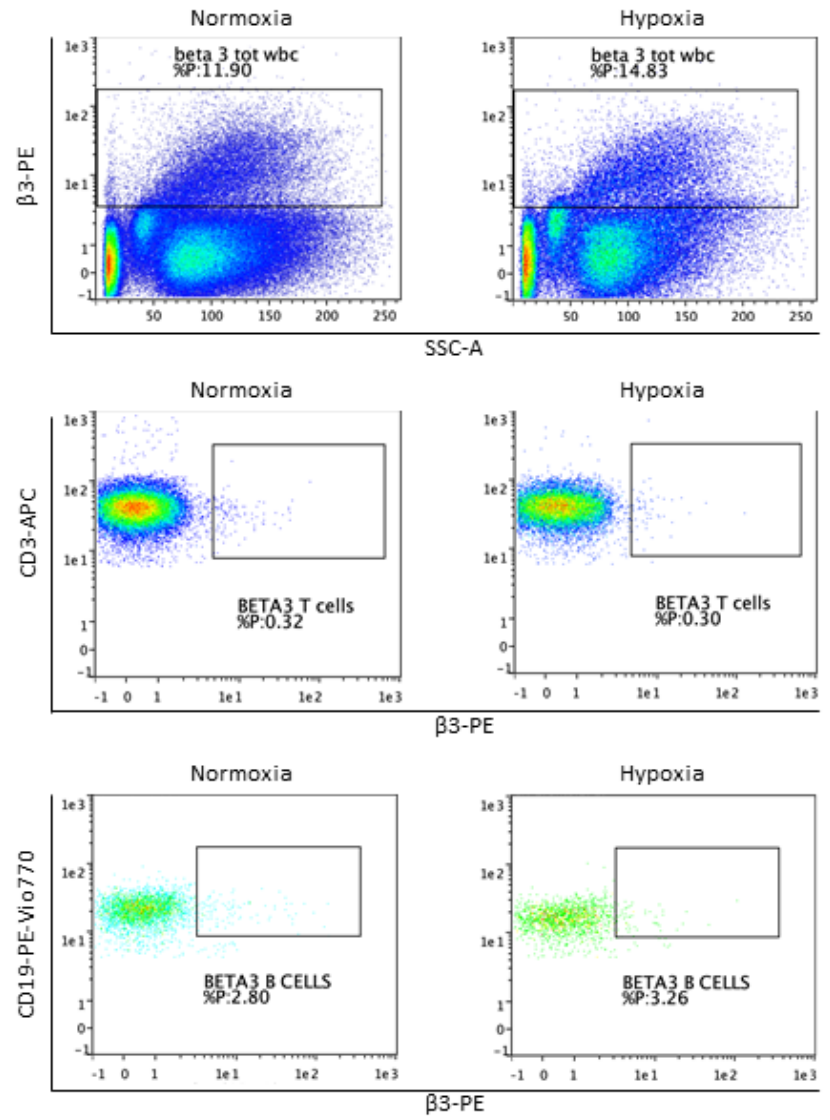

D)

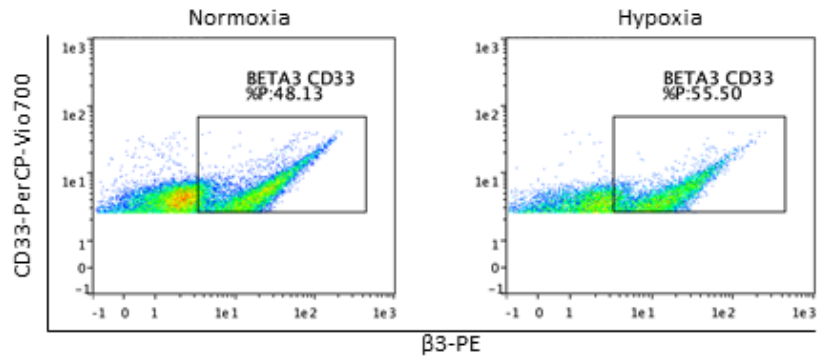

F)
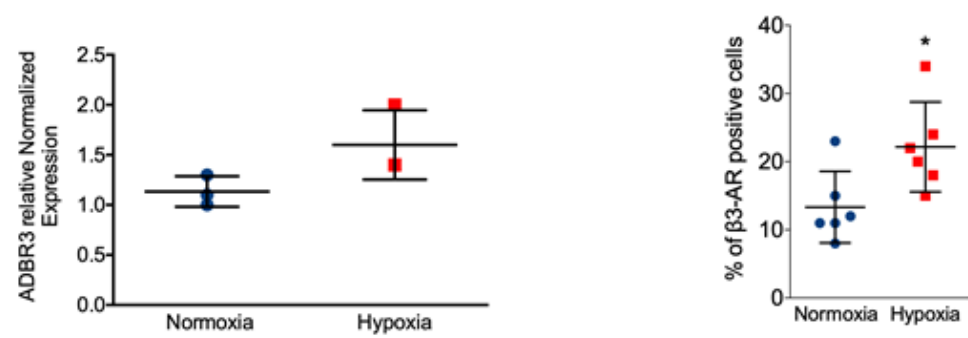

Figure 4. Evaluation of $\beta 3-\mathrm{AR}$ expression in BMCs and peripheral blood mononuclear cells (PBMCs) of healthy samples. (A) Flow cytometric plot showing $\beta 3$-AR expression on total PBMCs. (B) Flow cytometric plot showing $\beta 3$-AR expression on CD3 (T cells) positive cells. (C) Flow cytometric plot showing $\beta 3$-AR expression on CD19 (B cells) positive cells. (D) Flow cytometric plot showing $\beta 3$-AR expression on CD33 (myeloid cells) positive cells. (E) Real-time PCR showing $\beta 3$-AR mRNA expression in PBMCs in normoxia $\left(21 \% \mathrm{O}_{2}\right)$ and hypoxia $\left(1 \% \mathrm{O}_{2}\right)$. (F) $\beta 3$-AR positive cells in BMCs under normoxia and hypoxia, evaluated through cytofluorimetric analysis. Results are reported as mean $\pm \mathrm{SD}$ of three independent experiments. $\mathrm{n}=3$ per group. ${ }^{*} P<0.05$ hypoxia vs. normoxia. 
A)

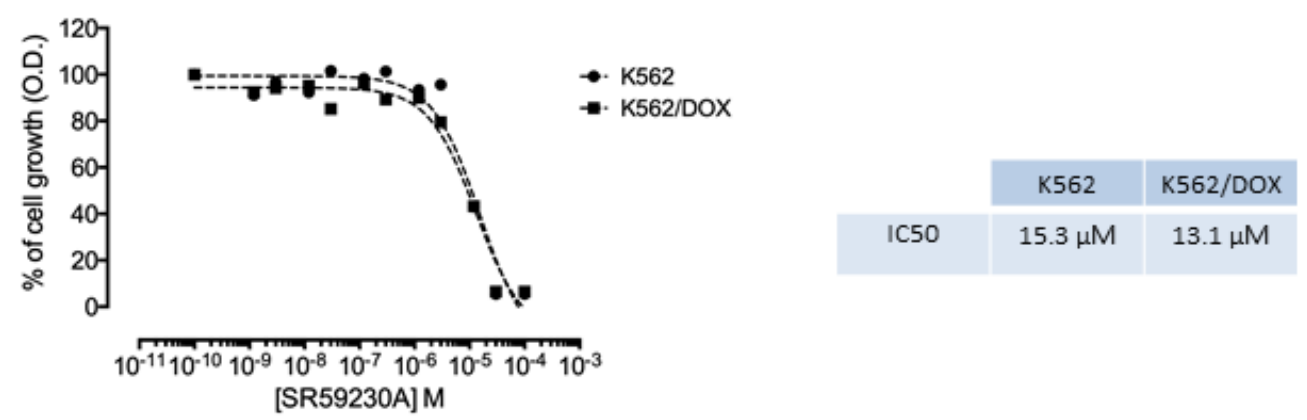

B)

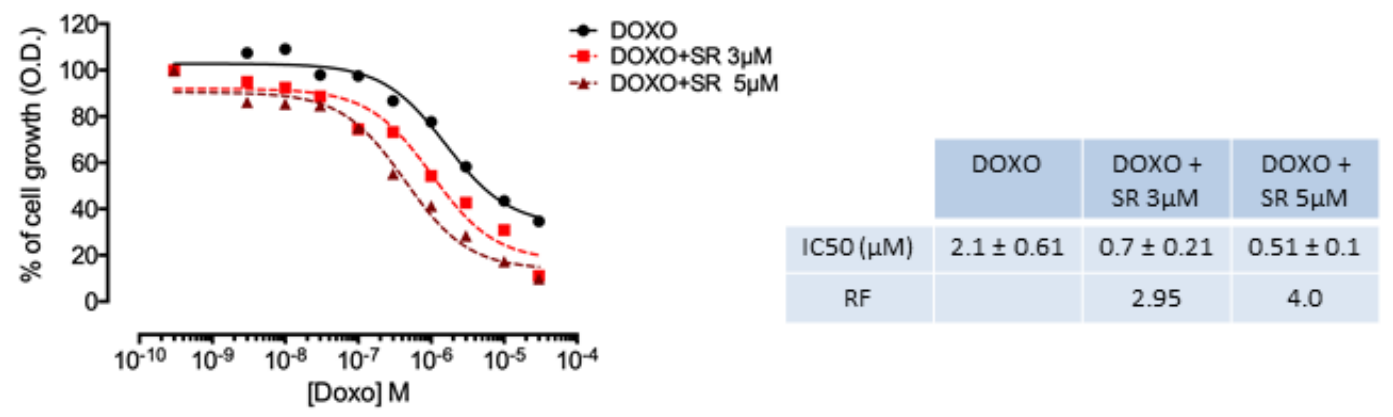

Figure 5. Evaluation of cytotoxicity of SR59230A and SR59230A/doxorubicin combination. (A) Intrinsic cytotoxicity of SR59230A evaluated on K562 cell line and K562/DOX cell line resistant to doxorubicin due to P-glycoprotein (P-gp) overexpression. The table shows $\mathrm{IC}_{50}$ values obtained with SR59230A; (B) Cytotoxicity curves of doxorubicin in the absence and in the presence of two concentrations of SR59230A ( $3 \mu \mathrm{M}$ and $5 \mu \mathrm{M})$ in K562/DOX cell line. Average $\mathrm{IC}_{50}$ values \pm error standard of doxorubicin and its combination with the SR59230A are reported. The table also shows the reversal fold (RF) value calculated from the ratio between the $\mathrm{IC}_{50}$ value of doxorubicin in the absence of SR59230A and in the combination with the compound under study. Results are reported as mean of three independent experiments.

As shown in Figure 5B, SR59230A seemed to increase the sensitivity of the K562/DOX cell line to doxorubicin, producing a reversal fold (RF) of 2.95 with the $3 \mu \mathrm{M}$ concentration and of 4 with the $5 \mu \mathrm{M}$ concentration under normoxic condition. The RF values are derived from a reduction in the $\mathrm{IC}_{50}$ values for doxorubicin which stand at $2.1 \pm 0.61 \mu \mathrm{M}, 0.7 \pm 0.21 \mu \mathrm{M}$ and $0.51 \pm 0.1 \mu \mathrm{M}$ for anthracycline in the absence of SR59230A and in the presence of SR59230A ( $3 \mu \mathrm{M}$ and $5 \mu \mathrm{M}$, respectively).

A preliminary study was conducted on the K562 cell line to investigate a putative role of the $\beta 3-A R$ in multidrug resistance (MDR). According to literature [18], the hypoxic environment should increase the expression of P-gp; therefore, the response of the K562 and K562/DOX cell lines to hypoxic exposure was assessed. As shown in Figure 6A, K562 cell line in a hypoxic environment moderately increased the expression of P-gp compared with the same condition in K562/DOX cell line. K562/DOX cell line revealed higher expression of P-gp and a strong induction under hypoxic conditions. Cytotoxicity of doxorubicin increased significantly with RF of 14.2 in K562 cell line exposed to hypoxia (Figure 6B and Supplementary Figure S1B). Moreover, results showed that SR59230A decreased P-gp protein expression both at $3 \mu \mathrm{M}$ and $5 \mu \mathrm{M}$ under hypoxic conditions (Figure 6C). Figure 6D shows the fluorescence curves obtained with the CD243 antibody specific for P-gp; the figure shows that the protein is overexpressed in the resistant cell line with a fluorescence ratio of 17.3. 
A)

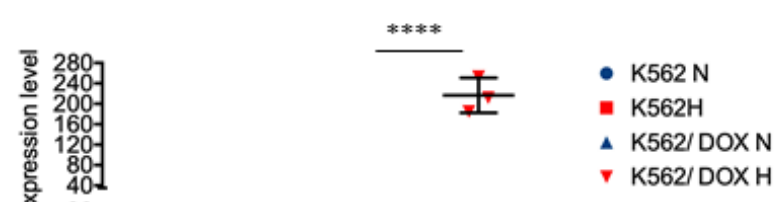

武

B)

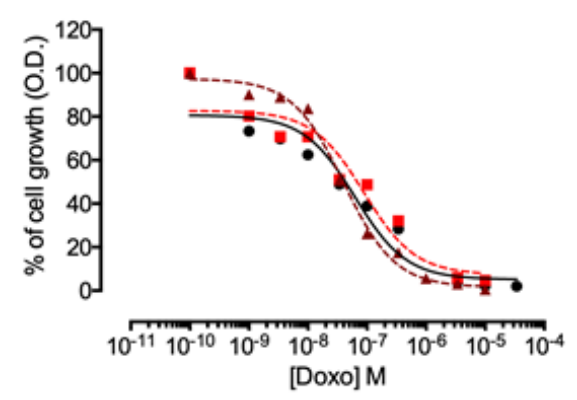

Hypoxia

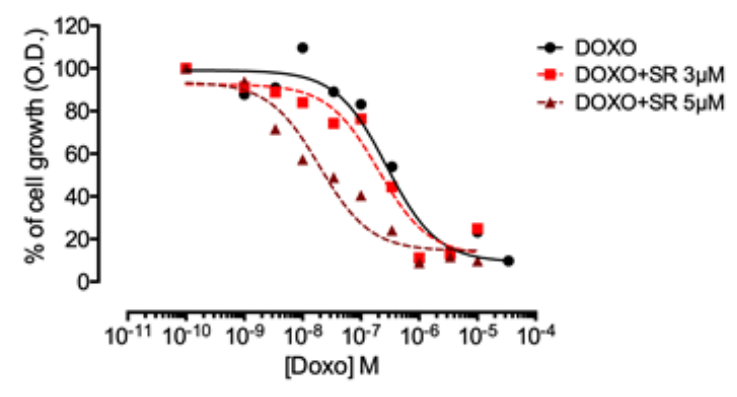

D)
C)

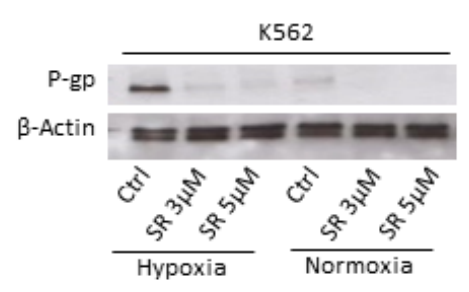

E)

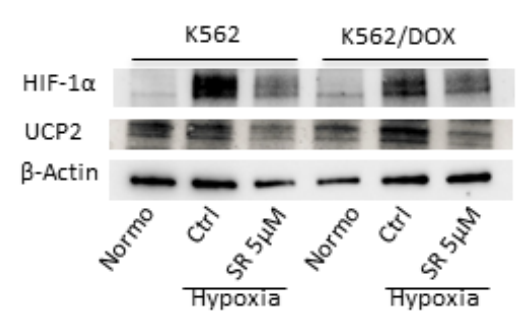

K562

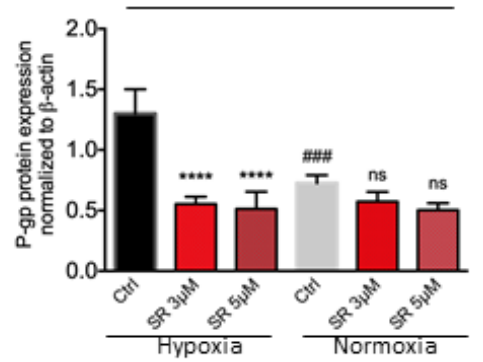

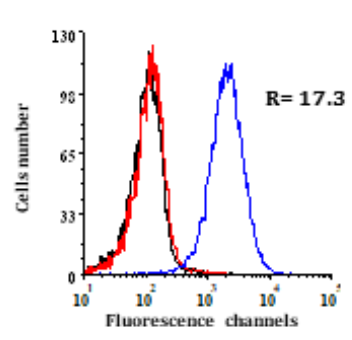
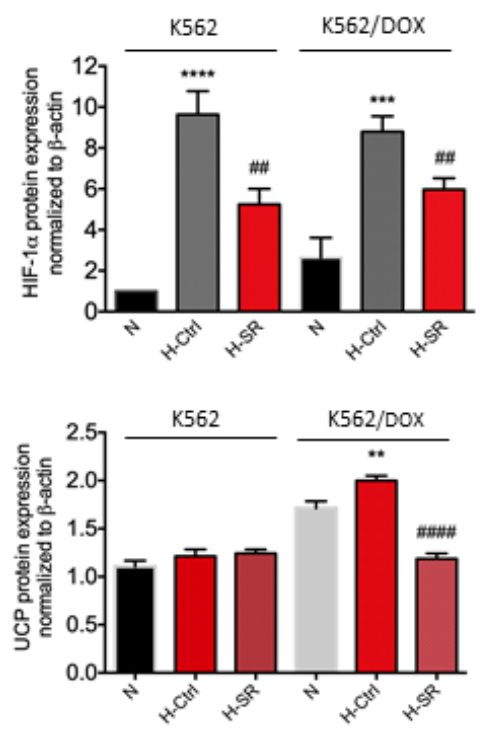

Figure 6. P-gp, HIF- $1 \alpha$ and UCP2 expression, and evaluation of cytotoxicity of SR59230A and SR59230A/doxorubicin combination. (A) Real-time PCR analysis: P-gp mRNA expression assessed in $\mathrm{K} 562$ and $\mathrm{K} 562 / \mathrm{DOX}$ cell lines under hypoxia $\left(1 \% \mathrm{O}_{2}\right)$ and normoxia $\left(21 \% \mathrm{O}_{2}\right)$; significance was 
calculated by one-way ANOVA analysis followed by Bonferroni's post-hoc test. Results are reported as mean \pm SD of three independent experiments. $n=3$ per group. (B) Cytotoxicity curves of doxorubicin in normoxia and hypoxia in the absence and in the presence of two concentrations of SR59230A $(3 \mu \mathrm{M}$ and $5 \mu \mathrm{M})$ in $\mathrm{K} 562$ cell line. Results are reported as mean of three independent experiments. (C) Western blot analysis showing P-gp expression in K562 cells treated with SR59230A at $3 \mu \mathrm{M}$ and $5 \mu \mathrm{M}$ under hypoxia and normoxia. Significance was calculated by one-way ANOVA analysis followed by Bonferroni's post-hoc test. Results are reported as mean \pm SD of three independent experiments. $n=$ 3 per group. (D) Fluorescence curves obtained with a FACScanto flow cytometer. $\mathrm{R}=$ ratio between the mean fluorescence intensity of resistant cells and parental cells. K562 cells (red) and K562/DOXO cells (blue), black curve: autofluorescence. (E) Western blot analysis showing HIF-1 $\alpha$ and UCP2 expression in K562 and K562/DOXO cells treated with SR59230A at $5 \mu \mathrm{M}$ under hypoxia and relative control in normoxia. Significance was calculated by one-way ANOVA analysis followed by Bonferroni's post-hoc test. Results are reported as mean \pm SD of three independent experiments. $n=3$ per group.

According to Calvani et al., UCP-2 is strongly expressed in various cancer types, among which leukemia and pancreatic cancer. Moreover, UCP-2 overexpression is regulated by $\beta 3-\mathrm{ARs}$ in stem cells [15]. Furthermore, literature data showed that UCP-2 is involved also in cancer resistance, especially in paclitaxel resistance of lung cancer, in topoisomerase I inhibitor CPT-11 resistance of colon cancer and in gemcitabine resistance of pancreatic adenocarcinoma, non-small cell lung adenocarcinoma and bladder carcinoma [19]. Interestingly, it has been also reported in leukemia that genipin, an UCP-2 inhibitor, sensitized drug-resistant cells to anthracyclin [20].

Therefore, in this report, we treated K562 both sensitive and resistant to doxorubicin with SR59230A. Results showed that, in K562 resistant cell line, SR59230A inhibited the upregulation of UCP2 observed in hypoxia compared to normoxia conditions (Figure 6E).

Moreover, we observed also that HIF-1a protein expression induced in hypoxia was reverted by treatment with SR59230A (Figure 6E), confirming that the $\beta 3$-AR could affect MDR-1 expression by regulating the HIF-1a protein levels.

\section{Discussion}

Literature data showed that $\beta$-ARs blockade could be involved in prevention and treatment of different types of tumor [21]. Preclinical and clinical efficacy of $\beta$-ARs blockade in numerous cancers, including breast cancer, melanoma, angiosarcoma, neuroblastoma, pancreatic adenocarcinoma, ovarian and prostate cancer, has been demonstrated [22]. For instance, Montoya et al. showed that $\beta$-ARs antagonists may promote a reduction of tumor proliferation not only in localized breast tumors [23], but also in advanced stages [22]. Concerning blood cancer, Lamkin et al. showed through in vivo models that chronic stress can enhance the progression of human pre-B cell acute lymphoblastic leukemia involving $\beta$-adrenergic signaling [12]. Nevertheless, currently the role of $\beta$-AR antagonists in myeloid malignancies has not been clarified yet.

In order to better understand the role of $\beta 3$-AR in myeloid malignancies, we focused our attention on the effect of the $\beta 3$-AR antagonist SR59230A on this type of tumor; in particular, we used K562, KCL22, HEL and HL60 myeloid leukemia cell lines and we demonstrated that $\beta 3$-AR blockade results in reduced cancer cell lines survival by increasing apoptosis, especially under hypoxic conditions.

The finding that SR59230A enhances cell lines death supports the idea that $\beta 3$-AR could influence biological processes involved in the regulation of the balance between cell growth and apoptosis. To confirm that $\beta 3-\mathrm{AR}$ could play a crucial role in disease condition, and especially in cancer, we analyzed BM and PBMCs samples from healthy donors as control samples. SR59230A was selective for myeloid leukemia malignancies and non-toxic for normal cells, demonstrating that $\beta 3$-AR could be a possible marker for malignancies.

Literature data have already shown the $\beta 3$-AR upregulation under hypoxia in melanoma [16]; here we demonstrated that $\beta 3$-AR expression is increased in myeloid leukemia cell lines under hypoxia. Moreover, we observed an enhancement of apoptosis in $\beta 3$-AR positive cells after SR59230A treatment, 
suggesting that $\beta 3-A R$ could contribute to cancer cell lines survival. Our results suggest to better investigate the efficacy of $\beta 3$-AR blockers as potential drugs for myeloid leukemias treatment. $\beta 3$-AR is expressed in normal cells at low levels and more importantly is slightly induced by hypoxia compared with hypoxic induction in cancer cell lines. The expression of $\beta 3-A R$ in normal cells, in particular in BM, was reported by Méndez-Ferrer et al. showing the participation of the receptor in HSCs mobilization from the BM [24]. In particular, the authors discovered that adrenergic hormones, known for their involvement in bone remodeling binding $\beta 2$-ARs on osteoblasts, were also involved in the activation of $\beta 3$-ARs on the surface of BM stromal cells with consequent degradation of the Sp1 transcription factor, downregulation of the anchoring protein CXCL12 and finally HSCs mobilization from BM to bloodstream [24,25].

Since $\beta 3$-AR was slightly induced under hypoxic conditions in normal cells and hypoxia is a feature of different pathologies, this receptor could be a putative selective marker for cancer therapy and other pathologies involving hypoxic environment.

Furthermore, in this study we focused our attention on the potential effect of the $\beta 3$-AR antagonist SR59230A on myeloid leukemia's resistance to doxorubicin. Indeed, cancer MDR represents a significant clinical problem for cancer treatment, including hematological malignancies. Doxorubicin is an antineoplastic compound frequently used in different tumor types [26]; unfortunately, myeloid leukemia treatment often fails due to the development of resistance to doxorubicin. In general, MDR is a complex process associated with various mechanisms, including overexpression of $\mathrm{ABC}$ transporters, among which is P-gp, with consequent increase in drugs efflux [27].

Several studies evidenced the involvement of HIF1 $\alpha$ in the regulation of MDR1 gene expression in various tumors, including colon and liver cancer [28]. In particular, hypoxia promotes chemoresistance by enhancing MDR1 expression in tumor cells [28]; for instance, Xie et al. reported a correlation of HIF1 $\alpha$ expression and MDR1/Pgp expression in laryngeal cancer Hep 2 cells [28], while Ding et al. described this association in colon carcinoma [29]. Moreover, the relationship between HIF-1, hypoxia and P-gp has been described also in gastric cancer, gliomas and breast carcinoma [30]. Concerning hematologic malignancy, interestingly Muz et al. reported that hypoxia increased P-gp expression in an in vitro model of multiple myeloma [31].

In this work we showed that the combination of $\beta 3$-AR antagonist SR59230A with doxorubicin reduced resistance to doxorubicin in K562/DOX cell line, which represents a model of a doxorubicinresistant cell line with higher expression of P-gp in comparison with the K562 cell line.

We showed an increase in MDR1 expression in the K562 cell line maintained in hypoxia, consistent with the finding that hypoxia is involved in MDR [32]; we then evaluated the effect of SR59230A and doxorubicin combination on this parental cell line under normoxic and hypoxic conditions observing an increase in doxorubicin sensitivity in hypoxia in comparison with normoxia.

According to Comerford et al., MDR1 gene is hypoxia responsive: indeed, hypoxia promotes transcriptional induction of MDR1 and consequently P-gp expression [18]. Finally, the resistance reversion in K562 resistant to doxorubicin cell line treated with SR59230A suggests that SR59230A could act targeting P-gp or could be involved in the regulation of P-gp expression. We can therefore speculate that SR59230A may represent a novel interesting therapeutic strategy for myeloid leukemias treatment resistant to MDR drugs.

\section{Materials and Methods}

\subsection{Cell Lines and Culture Conditions}

Four different human myeloid leukemia cell lines were cultured in our study: K562 and KCL22 (chronic myelogenous leukemia cell lines), HEL (erythroleukemia cell line), HL60 (Acute Promyelocytic Leukemia cell line). Cell lines were obtained from ATCC. Cell lines were cultured in RPMI medium (Gibco) supplemented with 10\% fetal bovine serum (FBS), 1\% L-glutamine (200 mmol/L), $100 \mathrm{U} / \mathrm{mL}$ 
penicillin-streptomycin. All cell lines were maintained at $37^{\circ} \mathrm{C}$ in a $5 \% \mathrm{CO}_{2}$ humidified atmosphere incubator with $21 \% \mathrm{O}_{2}$ for normoxia, and $1 \% \mathrm{O}_{2}$ for hypoxia condition.

The P-gp expressing K562/DOX cell line was obtained from Prof. J. P. Marie (Hospital Hotel-Dieu, Paris, France). This cell line was cultured in RPMI 1640 medium (GIBCO) supplemented with $10 \%$ fetal calf serum (FCS) (GIBCO) at $37{ }^{\circ} \mathrm{C}$ in a humidified incubator with $5 \% \mathrm{CO}_{2}$. To maintain the resistance, every month, the resistant cell line was cultured for three days with $400 \mathrm{nM}$ doxorubicin. K562/DOX cell line overexpresses almost exclusively the membrane glycoprotein P-gp.

All cell lines were routinely tested for mycoplasma contamination.

\subsection{Intrinsic Cytotoxicity}

The intrinsic toxicity of the SR59230A compound was determined through MTT assay after the exposure of parental cell line, K562, and resistant cell line, K562/DOX, to the compound in a concentration range of $10^{10} \mathrm{M}$ to $10^{4} \mathrm{M}$ for $72 \mathrm{~h}$ in a humidified atmosphere with $5 \% \mathrm{CO}_{2}$. The MTT working solution was then added and plates were further incubated for $3 \mathrm{~h}$. Following incubation cells, formazan crystals were inspected microscopically. The supernatant was then carefully removed by slow aspiration and the formazan crystals were dissolved in $150 \mu \mathrm{L}$ of Dimethyl Sulfoxide (DMSO). The absorbance of the solution was then read on an automated plate reader at a wavelength of $570 \mathrm{~nm}$. The percentage of growth compared to the untreated control was transformed into dose-response curves with the GraphPad Prism 5 program and calculated the $\mathrm{IC}_{50}$ values. Toxicity test was repeated three times.

\subsection{Doxorubicin Toxicity}

The doxorubicin toxicity was evaluated in absence and in the presence of the SR59230A compound tested at $3 \mu \mathrm{M}$ and $5 \mu \mathrm{M}$ concentrations. Cells $\left(10^{4}\right.$ cells/well) were seeded, in exponential growth phase, and solutions of doxorubicin, or a solution of doxorubicin in combination with the compound, were added to the wells repeated in quadruplicate. Then the plates were incubated at $37^{\circ} \mathrm{C}$ for $72 \mathrm{~h}$ in a humidified atmosphere with $5 \% \mathrm{CO}_{2}$. The MTT test was applied as described for intrinsic toxicity and the ability of the SR59230A compound to increase cytotoxicity of doxorubicin was expressed by the $\mathrm{RF}$ values obtained as the ratio between the doxorubicin $\mathrm{IC}_{50}$ values on $\mathrm{K} 562 / \mathrm{DOX}$ cell line in the absence and in the presence of the compound. The same procedure was adopted for the evaluation after $48 \mathrm{~h}$ of the reversal activity of resistance in hypoxic environment with $1 \% \mathrm{O}_{2}$. The cell line was adapted to $\mathrm{O}_{2}$ decrease for $24 \mathrm{~h}$. At $48 \mathrm{~h}$, a sample of control cells maintained at $21 \% \mathrm{O}_{2}$ or $1 \% \mathrm{O}_{2}$ was collected for the molecular analysis by PCR. Toxicity test was repeated three times.

\subsection{Reverse Transcription RT-PCR}

The expression levels of MDR1 were analyzed through quantitative PCR (qRT-PCR) using a RotorGene 3000 (Qiagen, Germany) instrument. Primers were purchased from IDT (Germany). An amount of $500 \mathrm{ng}$ of total RNA was retro-transcribed using iScript (Bio-Rad, USA) and amplified with specific primers: MDR1, Fw CAGCTATTCGAAGAGTGGGCACAAAC and Rv GCCTCTGCATCAGCTGGACTGTTG. PCR amplification was carried out by SsoAdvancedTM Universal SYBR@Green Supermix (Bio-Rad, USA) according to manual instruction. In the present analysis 18s rRNA was confirmed to be stable and was used as the normalizer Fw CGGCTACCAC ATCCAAGGAA and Rv GTTATTTTTCGTCACTACCTCCCCGGG. The RT-qPCR was performed using the following procedure: $98{ }^{\circ} \mathrm{C}$ for $2 \mathrm{~min}, 40$ cycles of $98^{\circ} \mathrm{C}$ for $5 \mathrm{~s}, 60^{\circ} \mathrm{C}$ for $10 \mathrm{~s}$. The program was set to reveal the melting curve of each amplicon from 60 to $95^{\circ} \mathrm{C}$ with a read every $0.5^{\circ} \mathrm{C}$. For the ADRB3 gene the following primers were used: RefSeq Accession No. NC_000008.10, NG_011936.1, NT_167187.1; unique assay ID qHsaCED0047996 (Biorad). 


\subsection{BM and Culture Conditions}

The study was conducted in accordance with the Declaration of Helsinki, and the protocol was approved by the Pediatric Ethics Committee of Regione Toscana (Project identification code "Beta 3 2019 \#235/2019").

Peripheral Blood (PB) samples of BM blood were collected according to clinical management. $\mathrm{BM}$ aspirates were collected from health donors that provided a written informed consent. BMCs were isolated and expanded using $\alpha$ MEM supplemented with $10 \%$ heat inactivated FBS, penicillin-streptomycin, 4-(2-hydro-xyethyl)-1-piperazineethanesulfonic acid (HEPES), sodium pyruvate (all from Invitrogen, Mississauga, Ontario, Canada), and $5 \mathrm{ng} / \mathrm{mL}$ basic fibroblast growth factor (bFGF or FGF2; from Humanzyme, MedicorpInc., Montreal, Quebec, Canada). BMCs were incubated under standard conditions (at $37^{\circ} \mathrm{C}$ in a humidified incubator with $5 \% \mathrm{CO}_{2}$ ) at $21 \% \mathrm{O}_{2}$ or $1 \% \mathrm{O}_{2}$.

\subsection{Flow Cytometric Analysis and Apoptosis Evaluation}

K562, KCL22, HEL and HL60 cell lines were cultured in 24-well plates (50,000/well) in a hypoxic or normoxic incubator. In order to evaluate SR59230A toxicity, all cell lines were treated with increasing concentration of SR59230A $(1 \mu \mathrm{M}, 3 \mu \mathrm{M}, 6 \mu \mathrm{M}, 8 \mu \mathrm{M}, 10 \mu \mathrm{M})$ for $24 \mathrm{~h}$ and $48 \mathrm{~h}$.

SR59230A $(1 \mu \mathrm{M}, 5 \mu \mathrm{M}, 10 \mu \mathrm{M}, 20 \mu \mathrm{M}, 50 \mu \mathrm{M})$ effects on apoptosis were evaluated on BMCs cultured in 24 -well plates $(50,000 /$ well $)$ in hypoxic $(1 \%)$ or normoxic $(21 \%)$ conditions. For the evaluation of $\beta 1-, \beta 2-$, and $\beta 3$-adrenoreceptor expression level, K562, HEL and HL60 cell lines were cultured under normoxic and hypoxic conditions for $24 \mathrm{~h}$, and then stained with the anti- $\beta 1$ (ORB 129489 (PE)), anti- $\beta 2$ (ORB 15065 (FITC)) (Biorbyt, Caambridge, GB) and anti- $\beta 3-A R$ antibodies. The anti- $\beta 3-A R$ antibody (ab140713) used for cytofluorimetric analysis was obtained from ABCAM and conjugated with the R-Phycoerythrin Conjugation Kit (ab102918, ABCAM). Expression levels were obtained by using a MACSQuant Analyzer 10 flow cytometry.

Apoptosis was analyzed using FITC Annexin V Apoptosis Detection Kit with Propidium Iodide according to the manufacture's protocol. The cell lines were washed twice with cold BioLegend's Cell Staining Buffer and were resuspend in Annexin V Binding Buffer. FITC Annexin V and Propidium Iodide solution were added to cell suspension and further incubated for $15 \mathrm{~min}$ at room temperature in the dark; afterwards Annexin V Binding Buffer was added, the cell lines were analyzed by flow cytometry and data were analyzed with Flowlogic Software. Flow cytometry experiments were repeated 3 times.

\subsection{Colony Formation Assay}

Cord blood cells were obtained from health donors. For the colony formation assay, 100,000/mL of mononucleated cells was plated in p35 mm dishes in Methocult (GF H4434, Voden) and treated with SR59230A $(1 \mu \mathrm{M}, 5 \mu \mathrm{M}, 10 \mu \mathrm{M}, 20 \mu \mathrm{M}, 50 \mu \mathrm{M})$. After 14 days, the number of BFU-E and CFU-GM were counted.

\subsection{Western Blot Analysis}

After cells lysis and quantification, $20 \mu \mathrm{g}$ of total proteins was loaded on SDS-PAGE followed by WB analysis. PVDF membranes were treated with blocking solution for $1 \mathrm{~h}$ at room temperature and then they were incubated overnight at $4{ }^{\circ} \mathrm{C}$ with gentle shaking with the following primary antibodies: anti-human HIF-1a \#610959 (BD Transduction Laboratories), anti-MDR-1 (E1Y7S) \#13978 (Cell Signaling Technology), anti-UCP2 (G-6) sc-390189 and anti- $\beta$-Actin (C4) sc-47778 (Santa Cruz Biotechnology). The next day membranes were incubated with specific secondary antibodies for $1 \mathrm{~h}$ at room temperature. Chemiluminescent protein revelation was performed using Clarity Western ECL Substrate (Biorad) and the images were acquired through the Chemidoc Imaging System (Biorad () . The Western blot experiments were repeated three times and to verify the application of equal amounts 
of protein, the intensity of the corresponding protein bands of interest was normalized based on that of the $\beta$-actin band for each sample.

\subsection{Statistical Analysis}

Statistical analysis was performed using the GraphPad Prism 6.0 (GraphPad Software, San Diego, $\mathrm{CA})$. Values are presented as mean $\pm \mathrm{SD}$. Differences with $P<0.05$ were considered significant.

To assess normal distribution and homoscedasticity for each quantitative outcome in each group Kolmogorov-Smirnov's test and Bartlett's Test was used, respectively. In order to evaluate difference in quantitative outcomes between groups, according to normality and homoscedasticity tests results, ANOVA and posthoc t-test with Bonferroni correction for multiple comparison were used. Posthoc test was performed only if ANOVA analyses were statistically significant.

\section{Conclusions}

In summary, this work offers a new interesting perspective on myeloid leukemias treatment; in particular our data highlight $\beta 3-\mathrm{AR}$ as an attractive target to reduce cancer cell survival in myeloid malignancies (Figure 7). Moreover, $\beta 3$-AR antagonists in combination with MDR chemotherapeutic drugs, could represent a novel strategy to fight and overcome chemoresistance improving clinical outcome and survival of patients affected by myeloid leukemias. However, this work reported preliminary data that need validation through further experimental tests.

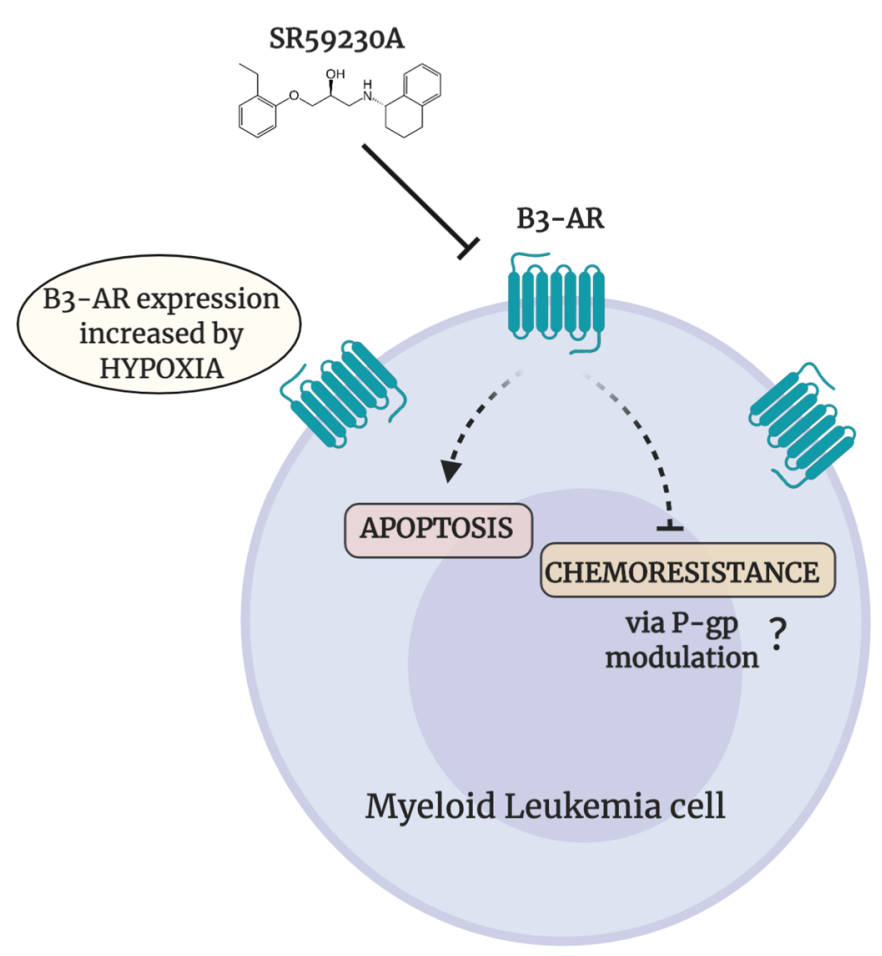

Figure 7. Schematic representation of effects elicited by $\beta 3$-AR-blockade in myeloid leukemia cell lines. Pharmacological SR59230A $\beta 3$-AR-blockade induces apoptosis and decreases chemoresistance in myeloid leukemia cell lines. Figure created with BioRender.

Supplementary Materials: The following are available online at http://www.mdpi.com/1422-0067/21/12/4210/s1. Figure S1. (A) Cell death assessment in myeloid leukemia cell lines silenced for $\beta 1-, \beta 2$ - and $\beta 3$-ARs in hypoxia and normoxia. Apoptosis evaluation through Annexin V and Propidium Iodide in HEL, K562, and HL60 cell lines transfected with selective siRNA for $\beta 1-, \beta 2-, \beta 3-$ ARs. (B) Average $\mathrm{IC}_{50}$ values of doxorubicin and its combination with the SR59230A (referring to Figure 6B). The table also shows the RF ( ${ }^{*}$ reversal fold) value calculated from the ratio between the $\mathrm{IC}_{50}$ value of doxorubicin in the absence of SR59230A and in the combination with the compound under study. Figure S2. (A) Cell death assessment in myeloid leukemia cell lines treated with L748,337 
and Propranolol in hypoxia and normoxia. $\beta$-ARs blockers effects on HEL, K562 and HL60 leukemia cell lines. Apoptosis evaluation through Annexin V in HEL, K562 and HL60 cell lines treated with different concentration of L748,337 $(5 \mu \mathrm{M}, 10 \mu \mathrm{M})$ and Propranolol $(5 \mu \mathrm{M}, 10 \mu \mathrm{M})$ for $48 \mathrm{~h}$, in normoxia $\left(21 \% \mathrm{O}_{2}\right)$ and in hypoxia $(1 \%$ $\mathrm{O}_{2}$ ); Significance was calculated by one-way ANOVA analysis followed by Bonferroni's post-hoc test. Results are reported as mean \pm SD of three independent experiments. $\mathrm{n}=3$ per group. $\left({ }^{*} P<0.05,{ }^{* *} P<0.01,{ }^{* * *} P<0.001\right.$ L748 or Prop vs. Ctrl Normoxia; ${ }^{\circ} P<0.05,{ }^{\circ} P<0.01,{ }^{\circ \circ \circ} P<0.001,{ }^{\circ \circ \circ \circ} P<0.0001$ L748 or Prop vs. Ctrl Hypoxia). (B) $\beta 1-\beta 2$ - and $\beta 3$-ARs protein expression in myeloid leukemia cell lines in hypoxia and normoxia. Evaluation of $\beta 1$-AR and $\beta 2$-AR positive cells in HEL, K562 and HL60 leukemia cell lines in normoxia and hypoxia.

Author Contributions: Conceptualization, M.C. and C.F.; G.l.M. and S.C. methodology; software, G.B.; validation, C.F., M.V. and M.C.; formal analysis, G.B.; investigation, C.B. and A.D.; resources, C.F.; data curation, M.C. and L.F.; writing-Original draft preparation, V.D.G. and M.C.; writing-Review and editing, A.D., G.B. and M.N.; visualization, M.C.; supervision, C.F., P.C. and A.M.V.; project administration, M.C.; funding acquisition, C.F. All authors have read and agreed to the published version of the manuscript.

Funding: Fondazione Meyer provided financial resources.

Acknowledgments: The authors wish to thank Angela Subbiani and Amada Pasha who kindly revised the manuscript.

Conflicts of Interest: The authors declare no conflict of interest. The funders had no role in the design of the study; in the collection, analyses, or interpretation of data; in the writing of the manuscript; or in the decision to publish the results.

\section{Abbreviations}

$\begin{array}{ll}\text { HSCs } & \text { Hematopoietic Stem Cells } \\ \text { P-gp } & \text { P-glycoprotein } \\ \text { ABC } & \text { ATP-binding Cassette } \\ \text { MDR1 } & \text { Multiple Drug Resistance gene } \\ \text { AML } & \text { Acute Myeloid Leukemia } \\ \beta \text {-ARs } & \text { beta-Adrenergic receptors } \\ \beta 1-A R s ~ & \text { beta1-adrenoreceptors } \\ \beta 2-A R s & \text { beta2-adrenoreceptors } \\ \beta 3-A R & \text { beta3-adrenoreceptor } \\ \text { BMCs } & \text { Bone Marrow Cells } \\ \text { PBMCs } & \text { Peripheral Blood Mononuclear Cells } \\ \text { RF } & \text { Reversal Fold } \\ \text { FBS } & \text { Fetal Bovine Serum } \\ \text { FCS } & \text { Fetal Calf Serum } \\ \text { DMSO } & \text { Dimethyl Sulfoxide } \\ \text { HEPES } & \text { 4-(2-hydro-xyethyl)-1-piperazineethanesulfonic acid } \\ \text { bFGF } & \text { basic Fibroblast Growth Factor }\end{array}$

\section{References}

1. Khaled, S.A.A.; Nabih, O.; Abdel Aziz, N.M.; Mahran, D.G. Myeloid Leukemias: A Glance at Middle Eastern Centers. J. Blood Med. 2019, 10, 425-433. [CrossRef]

2. Korn, C.; Méndez-Ferrer, S. Myeloid malignancies and the microenvironment. Blood 2017, 129, 811-822. [CrossRef]

3. Wang, X.; Zhang, H.; Chen, X. Drug resistance and combating drug resistance in cancer. Cancer Drug Resist. 2019, 2, 141-160. [CrossRef]

4. Zhang, J.; Gu, Y.; Chen, B. Mechanisms of drug resistance in acute myeloid leukemia. Onco Targets Ther. 2019, 12, 1937-1945. [CrossRef]

5. Talati, C.; Pinilla-Ibarz, J. Resistance in chronic myeloid leukemia: Definitions and novel therapeutic agents. Curr. Opin. Hematol. 2018, 25, 154-161. [CrossRef] [PubMed]

6. Soverini, S.; Mancini, M.; Bavaro, L.; Cavo, M.; Martinelli, G. Chronic myeloid leukemia: The paradigm of targeting oncogenic tyrosine kinase signaling and counteracting resistance for successful cancer therapy. Mol. Cancer 2018, 17, 49. [CrossRef] [PubMed] 
7. Nanayakkara, A.K.; Follit, C.A.; Chen, G.; Williams, N.S.; Vogel, P.D.; Wise, J.G. Targeted inhibitors of P-glycoprotein increase chemotherapeutic-induced mortality of multidrug resistant tumor cells. Sci. Rep. 2018, 8, 967. [CrossRef] [PubMed]

8. Schaich, M.; Soucek, S.; Thiede, C.; Ehninger, G.; Illmer, T. SHG AML96 Study Group. MDR1 and MRP1 gene expression are independent predictors for treatment outcome in adult acute myeloid leukaemia. Br. J. Haematol. 2005, 128, 324-332. [CrossRef] [PubMed]

9. Calvani, M.; Subbiani, A.; Vignoli, M.; Favre, C. Spotlight on ROS and $\beta 3$-Adrenoreceptors Fighting in Cancer Cells. Oxid. Med. Cell. Longev. 2019, 2019, 6346529. [CrossRef]

10. Cannavo, A.; Koch, W.J. Targeting $\beta 3$-Adrenergic Receptors in the Heart: Selective Agonism and $\beta$-Blockade. J. Cardiovasc. Pharmacol. 2017, 69, 71-78. [CrossRef]

11. Calvani, M.; Pelon, F.; Comito, G.; Taddei, M.L.; Moretti, S.; Innocenti, S.; Nassini, R.; Gerlini, G.; Borgognoni, L.; Bambi, F.; et al. Norepinephrine promotes tumor microenvironment reactivity through $\beta 3$-adrenoreceptors during melanoma progression. Oncotarget 2015, 6, 4615-4632. [CrossRef] [PubMed]

12. Lamkin, D.M.; Sloan, E.K.; Patel, A.J.; Chiang, B.S.; Pimentel, M.A.; Ma, J.C.; Arevalo, J.M.; Morizono, K.; Cole, S.W. Chronic stress enhances progression of acute lymphoblastic leukemia via $\beta$-adrenergic signaling. Brain Behav. Immun. 2012, 26, 635-641. [CrossRef] [PubMed]

13. Cole, S.W.; Sood, A.K. Molecular pathways: Beta-adrenergic signaling in cancer. Clin. Cancer Res. 2012, 18, 1201-1206. [CrossRef]

14. Chiarugi, P.; Filippi, L. $\beta 3$-adrenoreceptor and tumor microenvironment: A new hub. Oncoimmunology 2015, 4, e1026532. [CrossRef] [PubMed]

15. Calvani, M.; Cavallini, L.; Tondo, A.; Spinelli, V.; Ricci, L.; Pasha, A.; Bruno, G.; Buonvicino, D.; Bigagli, E.; Vignoli, M.; et al. $\beta 3$-Adrenoreceptors Control Mitochondrial Dormancy in Melanoma and Embryonic Stem Cells. Oxid. Med. Cell. Longev. 2018, 6816508. [CrossRef] [PubMed]

16. Dal Monte, M.; Casini, G.; Filippi, L.; Nicchia, G.P.; Svelto, M.; Bagnoli, P. Functional involvement of 33-adrenergic receptors in melanoma growth and vascularization. J. Mol. Med. (Berl). 2013, 91, 1407-1419. [CrossRef] [PubMed]

17. Rains, S.L.; Amaya, C.N.; Bryan, B.A. Beta-adrenergic receptors are expressed across diverse cancers. Oncoscience 2017, 4, 95-105. [CrossRef] [PubMed]

18. Comerford, K.M.; Wallace, T.J.; Karhausen, J.; Louis, N.A.; Montalto, M.C.; Colgan, S.P. Hypoxia-inducible Factor-1-dependent Regulation of the Multidrug Resistance (MDR1) Gene. Cancer Res. 2002, 62, 3387-3394.

19. Braun, N.; Klumpp, D.; Hennenlotter, J.; Bedke, J.; Duranton, C.; Bleif, M.; Huber, S.M. UCP-3 uncoupling protein confers hypoxia resistance to renal epithelial cells and is upregulated in renal cell carcinoma. Sci. Rep. 2015, 5, 13450. [CrossRef] [PubMed]

20. Dalla Pozza, E.; Fiorini, C.; Dando, I.; Menegazzi, M.; Sgarbossa, A.; Costanzo, C.; Palmieri, M.; Donadelli, M. Role of mitochondrial uncoupling protein 2 in cancer cell resistance to gemcitabine. Biochim. Biophys. Acta 2012, 1823, 1856-1863. [CrossRef]

21. Quốc Lu'o'ng, K.V.; Nguyễn, L.T. The roles of beta-adrenergic receptors in tumorigenesis and the possible use of beta-adrenergic blockers for cancer treatment: Possible genetic and cell-signaling mechanisms. Cancer Manag. Res. 2012, 4, 431-445. [CrossRef] [PubMed]

22. Montoya, A.; Varela-Ramirez, A.; Dickerson, E.; Pasquier, E.; Torabi, A.; Aguilera, R.; Nahleh, Z.; Bryan, B. The beta-adrenergic receptor antagonist propranolol alters mitogenic and apoptotic signaling in late stage breast cancer. Biomed. J. 2019, 42, 155-165. [CrossRef] [PubMed]

23. Montoya, A.; Amaya, C.N.; Belmont, A.; Diab, N.; Trevino, R.; Villanueva, G.; Rains, S.; Sanchez, L.A.; Badri, N.; Otoukesh, S.; et al. Use of non-selective $\beta$-blockers is associated with decreased tumor proliferative indices in early stage breast cancer. Oncotarget 2017, 8, 6446-6460. [CrossRef] [PubMed]

24. Méndez-Ferrer, S.; Lucas, D.; Battista, M.; Frenette, P.S. Haematopoietic stem cell release is regulated by circadian oscillations. Nature 2008, 452, 442-447. [CrossRef]

25. Scadden, D.T. Circadian Rhythms: Stem cells traffic in time. Nature 2008, 452, 416-417. [CrossRef]

26. Qinghong, S.; Shen, G.; Lina, S.; Yueming, Z.; Xiaoou, L.; Jianlin, W.; Chengyan, H.; Hongjun, L.; Haifeng, Z. Comparative proteomics analysis of differential proteins in respond to doxorubicin resistance in myelogenous leukemia cell lines. Proteome Sci. 2015, 13, 1. [CrossRef] [PubMed]

27. Nobili, S.; Lapucci, A.; Landini, I.; Coronnello, M.; Roviello, G.; Mini, E. Role of ATP-binding cassette transporters in cancer initiation and progression. Semin. Cancer Biol. 2020, 60, 72-95. [CrossRef] [PubMed] 
28. Xie, J.; Li, D.W.; Chen, X.W.; Wang, F.; Dong, P. Expression and significance of hypoxia-inducible factor- $1 \alpha$ and MDR1/P-glycoprotein in laryngeal carcinoma tissue and hypoxic Hep-2 cells. Oncol. Lett. 2013, 6, 232-238. [CrossRef]

29. Ding, Z.; Yang, L.; Xie, X.; Xie, F.; Pan, F.; Li, J.; He, J.; Liang, H. Expression and significance of hypoxia-inducible factor-1 alpha and MDR1/P-glycoprotein in human colon carcinoma tissue and cells. J. Cancer Res. Clin. Oncol. 2010, 136, 1697-1707. [CrossRef] [PubMed]

30. Chen, J.; Ding, Z.; Peng, Y.; Pan, F.; Li, J.; Zou, L.; Zhang, Y.; Liang, H. HIF-1 $\alpha$ inhibition reverses multidrug resistance in colon cancer cells via downregulation of MDR1/P-glycoprotein. PLoS ONE 2014, 9, e98882. [CrossRef] [PubMed]

31. Muz, B.; Kusdono, H.D.; Azab, F.; de la Puente, P.; Federico, C.; Fiala, M.; Vij, R.; Salama, N.N.; Azab, A.K. Tariquidar sensitizes multiple myeloma cells to proteasome inhibitors via reduction of hypoxia-induced P-gp-mediated drug resistance. Leuk. Lymphoma 2017, 58, 2916-2925. [CrossRef] [PubMed]

32. Cui, X.Y.; Skrettin, G.; Jing, Y.; Sun, H.; Sandset, P.M.; Sun, L. Hypoxia influences stem cell-like properties in multidrug resistant K562 leukemic cells. Blood Cells Mol. Dis. 2013, 51, 177-184. [CrossRef] [PubMed]

(C) 2020 by the authors. Licensee MDPI, Basel, Switzerland. This article is an open access article distributed under the terms and conditions of the Creative Commons Attribution (CC BY) license (http://creativecommons.org/licenses/by/4.0/). 